\title{
Project LITE: Light Inquiry Through Experiments
}

\section{K. Brecher}

K. Brecher, "Project LITE: Light Inquiry Through Experiments," Proc. SPIE 9663, Eighth International Topical Meeting on Education and Training in Optics and Photonics, 96632A (6 October 2003); doi: 10.1117/12.2208509

SPIE Event: Eighth International Topical Meeting on Education and Training in Optics and Photonics, 2003, Tucson, Arizona, United States 


\title{
Project LITE: light inquiry through experiments
}

\author{
K. Brecher \\ Department of Astronomy, Boston University, Boston, MA 02215 \\ 617-353-3423; brecher@bu.edu
}

\begin{abstract}
Project LITE: Light Inquiry Through Experiments" is a software, materials and curriculum development project. Its goal is to help undergraduates learn from direct eyes-on experience about light, optics, color and visual perception.
\end{abstract}

(C2003 Optical Society of America

OCIS codes: (000.2060) Education

\section{Introduction to Project LITE}

We are developing a suite of materials for use by undergraduates to learn about light. One is an optics kit with items carefully selected to be used interactively with the light emitted by a computer monitor controlled by a set of applets posted on the web at http://lite.bu.edu. Six "homelabs" utilizing these materials and software have been developed to date and trial tested at Boston University. They are about geometrical optics; diffraction; fluorescence and phosphorescence; color; polarization; and spectroscopy.

\section{Spectrum Explorer}

A second educational development focus is on spectroscopy. We are developing a software utility called the Spectrum Explorer that can help students learn about emission and absorption spectra; blackbody radiation, the Stefan-Boltzmann law and Wien's law; and their roles in astronomy, physics, chemistry and Earth science. We are also working on the development of two types of inexpensive spectrometers.

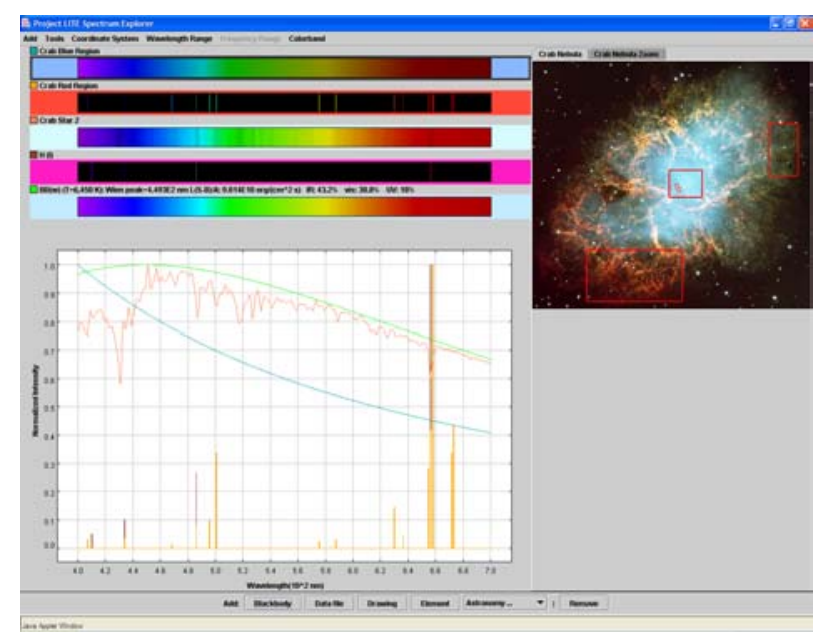

Fig. 1. Spectra of the Crab Nebula synchrotron continuum, red filamentary region, pulsar companion star with blackbody fit, and neutral atomic hydrogen displayed using the Spectrum Explorer software.

\section{LITE Vision}

We have also developed a set of interactive applets that let students explore a wide range of phenomena involving visual perception. Many of the effects are controllable and/or involve elements of time or motion available on a computer that cannot be experienced using standard static presentations in books.

\section{Research Support}

Project LITE is funded by the NSF Division of Undergraduate Education through Grant \# 0125992.

\footnotetext{
Eighth International Topical Meeting on Education and Training in Optics and Photonics, edited by Barry L. Shoop, Grover Swartzlander Jr., Proc. of SPIE Vol. 9663, 96632A

(C) 2003 SPIE, OSA, ICO · doi: 10.1117/12.2208509
} 